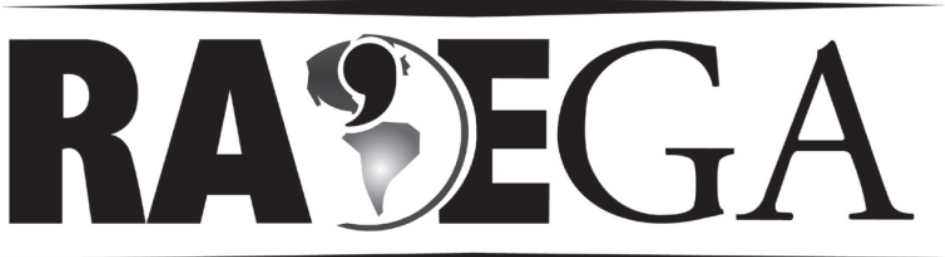

O ESPAÇO GEOGRÁFICO EM ANÁLISE

\title{
A SOLIDARIEDADE DO MEIO TÉCNICO-CIENTÍFICO- INFORMACIONAL NO PORTO DE NATAL-RN
}

\author{
The solidarity of the technical-scientific-informational \\ system in Natal port - RN
}

\author{
Francisco Fransualdo de Azevedo ${ }^{1}$ \\ Thatiana Bezerra Luiz ${ }^{2}$
}

\section{Resumo}

Os portos são sistemas de engenharia que permitem a efetivação de uma das atividades do sistema logístico, o transporte de cargas. Partindo dessa idéia, o presente trabalho busca compreender como se dá a movimentação dos principais produtos exportados pelo porto de Natal (melão, açúcar, manga, quartzo e camarão), e em que medida o meio técnico-científico-informacional contribui para a movimentação de tais mercadorias. Além disso, pôde-se verificar os aspectos estruturais e tecnológicos de alguns portos brasileiros. Para tanto, foram realizadas pesquisas bibliográficas, entrevistas e aplicação de questionários. Constata-se que o porto de Natal possui algumas lacunas que limitam seu desempenho na movimentação de mercadorias, prejudicando a fluidez do espaço.

Palavras-chave: Movimentação; Porto de Natal; Meio Técnico-científicoinformacional;

\footnotetext{
1 Bacharel em Ciências Econômicas, com estudos realizados na Universidade Católica de Santos - São Paulo (3 primeiros anos do curso) e Universidade do Estado do Rio Grande do Norte (2 últimos anos do curso). Licenciado em Geografia pela Faculdade Católica de Uberlândia - Minas Gerais. Mestre em Geografia pela Universidade Federal de Sergipe. Doutor em Geografia pela Universidade Federal de Uberlândia - Minas Gerais, com Estágio Doutoral na Universidade de Barcelona - Espanha. Atualmente é professor Adjunto do Departamento de Geografia da Universidade Federal do Rio Grande do Norte (Natal - RN - Brasil). ffazevedo@gmail.com

2 Bacharel em Geografia pela Universidade Federal do Rio Grande do Norte. Licencianda em Geografia pela Universidade Federal do Rio Grande do Norte. Natal - RN - Brasil. thatirio@yahoo.com.br
} 


\section{Abstract}

Ports are engineered systems that allow the execution of the cargo transportation that is an activity of logistic system. Based on this, this paper seeks to understand the movement of the main products exported on the Natal port (melon, sugar, mango, quartz and shrimp) and understand how to the technical-scientific-informational system can contribute to the movement of such goods. Moreover, it was verified the structural and technological aspects of some Brazilian ports through the literature scientific researches, interviews and questionnaires. Lastly, this paper indicates that the Natal port has gaps that limit their performance in the movement of goods, impairing the fluidity of space.

Keywords: Movement; Natal port; Technical-scientific-informational system.

\section{Introdução}

O Brasil apresenta uma costa de 8,5 mil quilômetros navegáveis, e um setor portuário que movimenta anualmente cerca de 700 milhões de toneladas de mercadorias e responde por mais de $90 \%$ das exportações. O transporte aquaviário possui um dos menores custos para o transporte de cargas no Brasil. De acordo com a Secretaria Especial de Portos (SEP) o sistema portuário brasileiro é composto por 37 portos públicos, entre marítimos e fluviais. Existem ainda 42 terminais de uso privativo e três complexos portuários que operam sob concessão à iniciativa privada.

A circulação de produtos suscita uma dinâmica espacial que envolve uma série de questões de ordem logística, como armazenagem, transporte e distribuição. O fato de ser componente de um sistema logístico evidencia a importância do transporte hidroviário do porto de Natal como elemento dessa circulação. Entretanto, para efetivação do fluxo de mercadorias se faz necessário considerar outros aspectos, como: equipamentos técnicos, infraestrutura portuária e a integração com outros modais de transporte. As tarifas portuárias também são um fator de relevância no que diz respeito à dinâmica de escoamento da produção, entretanto este fator não será analisado neste estudo.

Partindo dessa idéia, o trabalho busca compreender como se dá a circulação dos principais produtos exportados pelo porto de Natal, considerando o meio técnico-científico-informacional. 
O porto de Natal é responsável pelo escoamento de produtos que apresentam importância no contexto econômico do estado e que interagem com o mercado internacional. Para compreensão desse funcionamento serão considerados os produtos que apresentaram maior relevância quantitativa no contexto portuário natalense durante o período de 2005 a 2009. São eles: melão, açúcar, manga, quartzo e camarão.

A realização da pesquisa se deu a partir do levantamento bibliográfico de material relacionado ao tema, em livros, teses, artigos, periódicos, endereços eletrônicos, bem como em arquivos documentais da própria instituição em estudo. De posse do material encontrado foram elaborados fichamentos para melhor compreensão do tema e da realidade trabalhada.

Foram realizadas entrevistas junto aos responsáveis pelo porto de Natal e as duas armadoras que atuam no mesmo: Companhia Marítima de Afretamento / Companhia Geral Marítima (CMA CGM) e MARFRET. Além de visitas à área portuária para retirada de fotografias e para obtenção de conhecimento empírico de sua dinâmica. Foram aplicados ainda, questionários por meio de correio eletrônico, junto às empresas usuárias do serviço portuário inseridas no recorte da pesquisa. Por fim, os dados obtidos foram compilados e analisados para elaboração do trabalho final

O trabalho é relevante na medida em que contribui para a compreensão da movimentação de produtos exportados pelo porto de Natal e do modo como este atua nessa circulação, permitindo verificar aspectos que dizem respeito ao aparato estrutural e tecnológico do porto de Natal, bem como seus efeitos para a fluidez da produção e da dinâmica espacial. De acordo com Santos (2008a), apreender o movimento significa entender a dinâmica de funcionamento do espaço, apontando para a importância da circulação, cujos fluxos se revelam cada vez mais intensos, extensos e seletivos.

\section{Localização e caracterização do porto de Natal - RN}

O porto de Natal está situado à margem direita do rio Potengi a uma distância de aproximadamente $3 \mathrm{~km}$ de sua foz. Ele localiza-se no bairro da Ribeira, na cidade de Natal, capital do estado do Rio Grande do Norte, região 
Nordeste do Brasil (figura 01). Sua posição é estratégica no sistema hidroviário brasileiro e, portanto de fundamental importância no sistema logístico, pois sua proximidade com os continentes africano e europeu diminui despesas com o transporte e o tempo gasto para chegada dos produtos ao seu destino final.

\section{LOCALIZAÇÃO DO PORTO DE NATAL - RN}
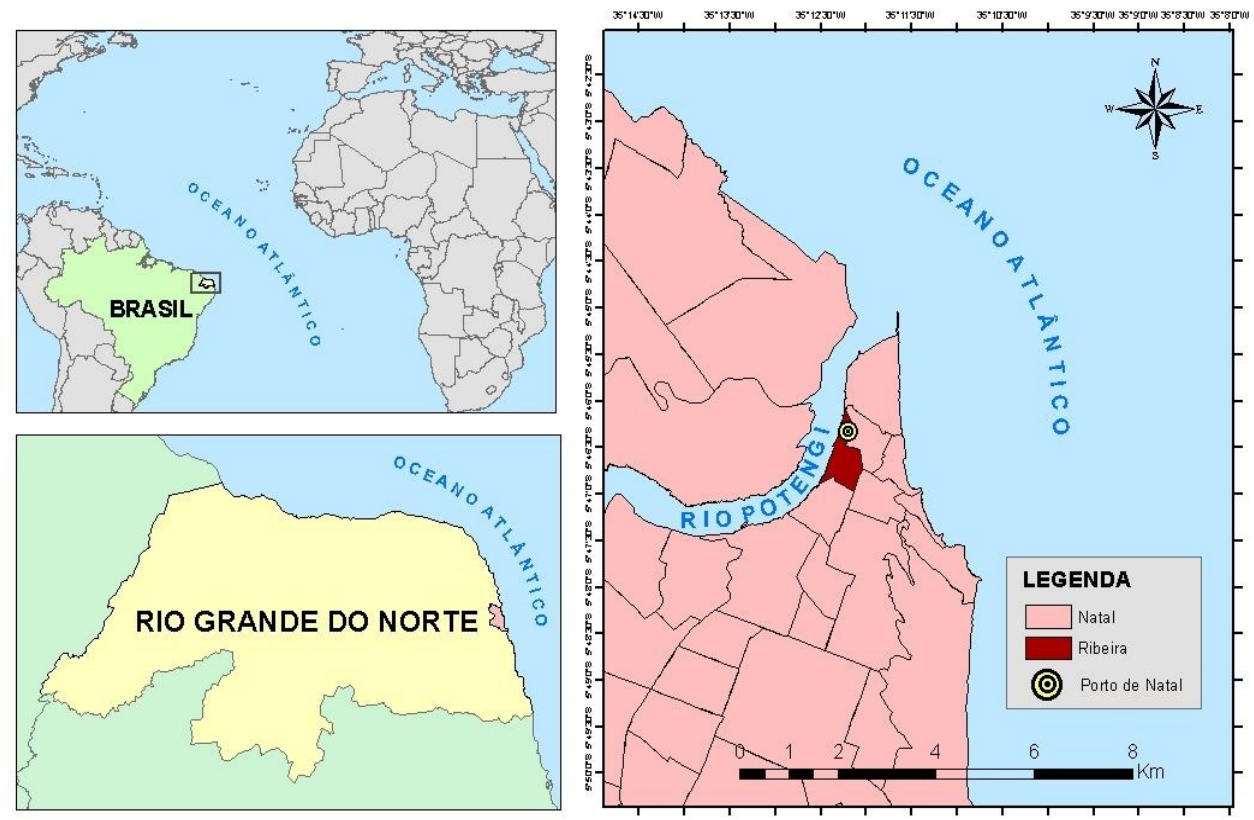

Figura 01 - Localização do Porto de Natal-RN

Elaboração própria (2010)

Os portos são elementos facilitadores da entrada e saída de cargas, entretanto o sistema de movimento aquaviário apresenta vantagens e desvantagens.

Este sistema tem como características principais: do ponto de vista econômico, o baixo custo relativo de transportes e a grande capacidade de carga; do ponto de vista topológico, possui grande rigidez, pois depende da existência das "hidrovias" para circular; do ponto de vista temporal, também apresenta desvantagens com relação a todos os outros sistemas de movimento, pois não autoriza velocidades altas em seus deslocamentos (CONTEL, 2004, p. 358).

Nesse sentido,

uma das características do presente período histórico é, em toda parte, a necessidade de criar condições para maior circulação dos homens, dos produtos, das mercadorias, do dinheiro, da informação, das ordens etc. Os países distinguem- 


\begin{abstract}
se, aliás, em função das possibilidades abertas a essa fluidez. Por isso um dos capítulos mais importantes a todos eles é a produção do seu equipamento, isto é, da criação ou aperfeiçoamento dos sistemas de engenharia que facilitam o movimento (SANTOS e SILVEIRA, 2004, p. 261).
\end{abstract}

Portanto, o porto de Natal é um sistema de engenharia, ou seja, uma infra-estrutura que facilita a movimentação de cargas e contribui para a integração do estado, com o mercado internacional, atendendo as atuais exigências econômicas de circulação de mercadorias e tornando os produtos mais competitivos.

Os portos são componentes de um sistema logístico, pois permitem a concretização de uma de suas atividades, o transporte, possibilitando a movimentação da produção. Entretanto, em virtude da "rigidez" do transporte hidroviário se faz necessário a utilização de outros modais de transporte, como: rodoviário, ferroviário e aeroviário. Essa integração entre os diversos modais é chamada transporte multimodal. No caso específico de Natal a integração é rodoviário-hidroviário. A cidade é interligada a todas as regiões do Nordeste e do Brasil por diversas rodovias federais. Ao sul pela BR 101 e a oeste pela BR 226, ambas encontram-se com a BR 406 e com a BR 304. Deste modo, as vias rodoviárias são um dos elementos que contribuem para fluidez da circulação.

O porto de Natal é administrado pela Companhia Docas do Rio Grande do Norte (Codern), empresa de economia mista, vinculada ao Ministério dos Transportes. Segundo a Codern, circulam pelo porto de Natal em média 300.000 toneladas de cargas anualmente, sendo estas predominantemente de exportação.

Dentre as cargas exportadas estão principalmente as frutas, como o melão, que possui maior evidência, a manga, o abacaxi, o mamão, a banana, a uva, a melancia, entre outras, que juntas ocupam aproximadamente $30 \%$ do total de produtos movimentados pelo porto. No entanto, o porto de Natal exporta outros tipos de mercadorias que isoladamente também apresentam significância, entre elas merece destaque o açúcar, o quartzo e o camarão. Outros produtos de menor representatividade quantitativa são: inhame, pedras, tecidos, peixe, pirulito, gasolina, óleo diesel, etc. No que diz respeito as importações, o produto que se destaca é o trigo. 
Como se pode perceber a fruticultura é responsável por boa parte da movimentação de mercadorias, entretanto, sua demanda pelo porto obedece ao período de safra, que vai de agosto à março. Por esse motivo, nos meses restantes, de entressafra, embora haja procura por parte de outros usuários, o porto apresenta capacidade ociosa.

O transporte marítimo pode ser dividido em três formas de navegação, são elas: a cabotagem que é navegação realizada entre portos ou pontos do território brasileiro, utilizando a via marítima ou entre esta e as vias navegáveis interiores (até, aproximadamente, 12 milhas da costa); a navegação interior que é realizada em hidrovias interiores, em percurso nacional ou internacional e por fim, a navegação de longo curso, realizada entre portos brasileiros e estrangeiros. A navegação de cabotagem realizada pelo porto de Natal é insignificante. Sua principal forma de navegação é a de longo curso.

O transporte de mercadorias é efetuado pelas armadoras francesas CMA CGM e MARFRET, que atuam numa parceria chamada joint venture. Neste tipo de parceria, as empresas se associam, com o intuito de compartilhar custos para reduzi-los. Atualmente, existem 6 navios operando na linha semanal do porto de Natal, sendo 4 deles da CMA CGM e 2 da MARFRET. O espaço destinado aos contêineres no navio é acordado pelas armadoras anualmente ou por safra, é o chamado alocation, que é maior na CMA CGM do que na MARFRET. Caso o espaço reservado aos contêineres no navio não seja ocupado por uma das armadoras a outra pode ocupá-lo. A MARFRET em Natal é representada pela Agência Marítima Wilson, Sons.

As armadoras oferecem uma linha semanal com destino a Europa, passando pelos portos de Algeciras e Vigo, ambos na Espanha, Rotterdam na Holanda, Tilburyn na Inglaterra e Rouen e Le Havre na França. Saindo da Europa o navio retorna para o continente americano, passando pelos portos de Philipsburg, nas Antilhas, Port of Spain, em Trinidad e Tobago, Degrad Des Cannes, na Guiana Francesa, pelo porto de Belém e de Fortaleza no Brasil, recomeçando o percurso pelo porto de Natal.

Além da Europa, esporadicamente, são destinados navios à África, utilizados exclusivamente para o transporte de parte do açúcar produzido no 
estado. Esse tipo de transporte é chamado de afretamento e normalmente é feito por intermédio de agências marítimas.

A CMA CGM possui o serviço "cadeia logística porta a porta”, onde o exportador pode movimentar sua mercadoria, desde a origem até o destino final, utilizando o transporte oferecido pela mesma. Já a MARFRET possui o serviço "porto a porto", que é exclusivamente aquático, ou seja, o exportador pode transportar sua mercadoria nos países de destino através de pequenas embarcações.

Com relação ao setor turístico, durante a alta temporada, o porto recebe semanalmente embarcações de Fernando de Noronha e esporadicamente transatlânticos, em cruzeiros internacionais. Ele pleiteia um terminal marítimo de passageiros, para oferecer melhores condições de infra-estrutura aos turistas que visitam a cidade.

No que diz respeito aos órgãos intervenientes na operação portuária, o porto de Natal dispõe de uma central de atendimento operacional, com área de $700 \mathrm{~m}^{2}$, que acomoda Polícia Federal, Receita Federal, Delegacia do Ministério da Agricultura, Vigilância Sanitária, Órgão Gestor de Mão-de-Obra (OGMO) e Operadores Portuários.

O porto de Natal apresenta um canal de acesso com largura média de $110 \mathrm{~m}$, extensão de $3 \mathrm{~km}$ e $10 \mathrm{~m}$ de profundidade. Seu cais comercial possui $540 \mathrm{~m}$ de frente acostável com 3 berços sendo 2 de $200 \mathrm{~m}$ de comprimento e $12 \mathrm{~m}$ de largura e um de $140 \mathrm{~m}$ de comprimento e $17 \mathrm{~m}$ de largura, com profundidade de $11,5 \mathrm{~m}$ em toda a extensão. Suas instalações de armazenagem são constituídas por 2 armazéns com área de $1.800 \mathrm{~m}^{2}$ cada, 2 galpões contíguos aos armazéns com áreas respectivas de $456 \mathrm{~m}^{2}$ e $380 \mathrm{~m}^{2}$ cada um, 1 armazém frigorífico com área de $2.418 \mathrm{~m}^{2}$, capacidade estática para $2.000 t$ e um terminal de contêineres com área de $15.000 \mathrm{~m}^{2}$. Além disso, é dotado de empilhadeiras do tipo reach stacker e top loader que permitem a movimentação dos contêineres. Estes equipamentos e infra-estruturas são parte da materialidade que permite a movimentação e a circulação de mercadorias e dessa forma, fluxos mais ou menos intensos e eficazes. 
Parte do espaço físico portuário é arrendado a empresas privadas. A Grande Moinho Potiguar e Indústria de Massas Ltda. ocupa $1.450 \mathrm{~m}^{2}$, onde funciona o conjunto industrial moageiro, compreendido de silos para recepção e armazenagem de trigo e industrialização de massas, biscoitos e outros derivados. A área total da empresa é em torno de $13.000 \mathrm{~m}^{2}$, com capacidade de recepção de 20.000 toneladas por mês e capacidade estática para moagem de 15.000t. O porto é arrendado ainda pela Lauritzencool do Brasil Ltda., que ocupa uma área total equivalente a $5.455 \mathrm{~m}^{2}$, onde se encontram instalados e em operação 02 armazéns, sendo um deles frigorífico. Sua área é de $2300 \mathrm{~m}^{2}$ com capacidade estática de armazenagem para 2000 toneladas de produtos, dispostas em seis câmaras frigoríficas independentes. O outro armazém ocupa uma área correspondente a $1.875 \mathrm{~m}^{2}$.

Nas proximidades do porto público, cerca de $50 \mathrm{~m}$ ao norte do cais, encontra-se o Terminal Petroleiro Píer das Dunas, privativo da Petrobrás, destinado a movimentação de granéis líquidos, constituído de 3 dolfins de atracação, com profundidade de acostagem de $10 \mathrm{~m}$ e em condições de fornecer combustível para as embarcações.

\title{
O espaço geográfico e a solidariedade do meio técnico- científico-informacional na movimentação de mercadorias
}

\section{Os portos e o espaço geográfico}

\begin{abstract}
Partindo da idéia de Milton Santos,
O espaço é formado por um conjunto indissociável, solidário e também contraditório, de sistemas de objetos e sistemas de ações, não considerados isoladamente, mas como o quadro único no qual a história se dá [...] Através da presença desses objetos técnicos: hidroelétricas, fábricas, fazendas modernas, portos, estradas de rodagem, estradas de ferro, cidades, o espaço é marcado por esses acréscimos, que lhe dão um conteúdo extremamente técnico (SANTOS, 2008a, p. 63)
\end{abstract}

Desse modo, os portos fazem parte de um sistema de objetos e como tais são submetidos a um sistema de ações que permitem a circulação de mercadorias, contribuem para o aumento da fluidez e imprimem uma dinâmica 
espacial. Entretanto, a efetivação de suas funções demanda uma série de outros elementos que também irão contribuir para concretização dessa circulação.

O espaço do qual o porto faz parte é solidário na medida em que apresenta objetos complementares a sua constituição como: as estradas, os caminhões, os contêineres, as empilhadeiras, os guindastes, assim como também os navios e todos os equipamentos necessários ao seu funcionamento. E a partir do momento em que as empresas usuárias se associam para exportar seus produtos com menores gastos utilizando contêineres conjuntamente. Esta solidariedade também ocorre com as empresas armadoras, que também se associam para obter menores custos de transporte.

O espaço é contraditório, pois num dado momento um determinado objeto pode ser muito utilizado e noutro deixar de ser, como é o caso da "substituição" dos navios cargueiros por navios porta-contêineres. A discussão realizada por Goebel pode ser trazida como exemplo dessa contraditoriedade, na qual

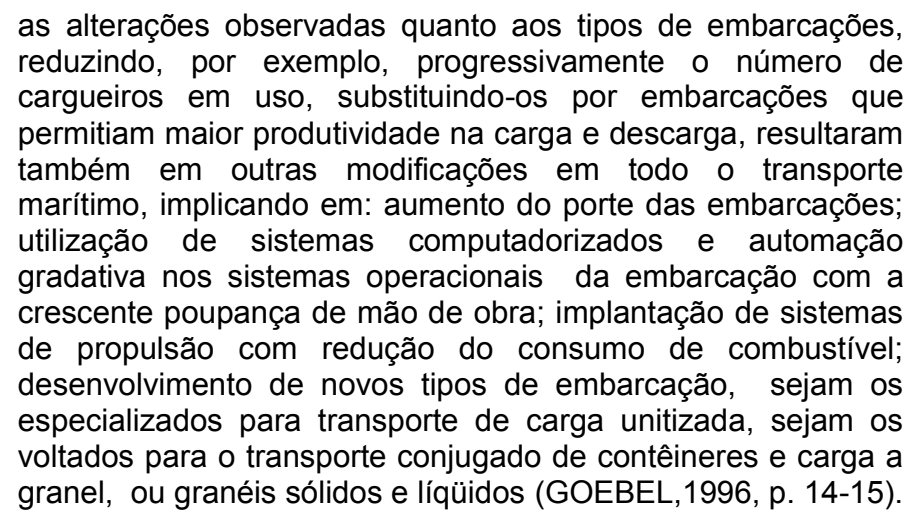

Percebe-se, a substituição de certos objetos, por outros que exerçam suas funções de maneira melhor que os primeiros, além da dependência desses novos objetos por objetos que viabilizem seu funcionamento. De acordo com Santos (1997), "os objetos criados para permitir a produção econômica, formas geradas para tornar possível a vida institucional e cultural, se tornam extremamente precárias, subordinadas a mudanças rápidas e profundas". Para 
este autor (2005, p. 25), estaríamos diante de um determinismo de um tipo novo, de um neodeterminismo do espaço artificial, e isso tanto mais quanto a produção considerada é moderna. Ou seja, estaríamos totalmente dependentes de objetos técnico-científicos, para execução de nossas atividades ou produção.

Prosseguindo na compreensão de espaço de Milton Santos (2008a, p. 73), o enfoque geográfico supõe a existência dos objetos como sistemas e não apenas como coleções: sua utilidade atual, passada, ou futura vem do seu uso combinado pelos grupos humanos que os criaram ou que os herdaram das gerações anteriores. Seu papel pode ser apenas simbólico, mas, geralmente, é também funcional. Esse sistema de objetos pode se dar, por exemplo, através do uso combinado do contêiner, do caminhão, do guindaste e do navio, onde a mercadoria é armazenada no contêiner, transportada pelo caminhão, movimentada pelo guindaste e levada pelo navio para o porto de desembarque. Santos trabalha essa idéia dizendo que

\begin{abstract}
cada objeto é, em si mesmo, um sistema, funcionando sistematicamente. Um grande supermercado ou Shopping Center seriam incapazes de existir se não fossem servidos por vias rápidas, estacionamentos adequados e acessíveis, sistemas de transportes públicos com horários regulares e conhecidos e se, no seu próprio interior, as atividades não estivessem subordinadas a uma coordenação. Esse é o caso dos grandes edifícios, dos armazéns, dos silos etc. Os portos, a rede rodoviária de um país, e, sobretudo, a rede ferroviária são exemplos de objetos complexos e sistêmicos (SANTOS, 2008a, p. 219)
\end{abstract}

De acordo com Santos (2008a),

as ações resultam de necessidades, naturais ou criadas. Essas necessidades: materiais, imateriais, econômicas, sociais, culturais, morais, afetivas, é que conduzem os homens a agir e levam a funções. Essas funções, de uma forma ou de outra, vão desembocar nos objetos. Realizadas através de formas sociais, elas próprias conduzem à criação e ao uso de objetos, formas geográficas. O sistema de ações são as relações sociais estabelecidas, que levam a criação de objetos novos ou se realizam sobre os objetos preexistentes.

Ainda segundo este autor,

Os objetos não agem, mas, sobretudo no período histórico atual, podem nascer predestinados a um certo tipo de ações, a cuja plena eficácia se tornam indispensáveis. São as ações que, em última análise, definem os objetos, dando-lhes sentido. Mas hoje, os objetos "valorizam" diferentemente as ações, em virtude de seu conteúdo técnico. Assim, considerar as ações separadamente ou os objetos separadamente, não dá conta da 
sua realidade histórica. Uma geografia social deve encarar, de modo uno, isto é, não-separado, os objetos e ações, "agindo" em concerto (SANTOS, 2008a, p. 86).

Portanto, o sistema de objetos e o sistema de ações não acontecem isoladamente. Eles se constituem em espaço, juntos, e dessa forma ajudam a apreender a totalidade.

Para compreensão da produção de espaço, Santos (1997) sugere sua divisão em quatro categorias de análise: forma, função, estrutura e processo. De acordo com o autor a forma é definida como uma estrutura técnica ou objeto responsável pela execução de determinada função. A função sugere uma tarefa ou atividade esperada de uma forma, pessoa, instituição ou coisa, é a atividade elementar de que a forma se reveste. A estrutura implica a interrelação de todas as partes de um todo; o modo de organização ou construção. E o processo pode ser definido como uma ação contínua, desenvolvendo-se em direção a um resultado qualquer, implicando conceitos de tempo (continuidade) e mudança.

Nesse sentido, as formas consideradas são o porto de Natal com sua infra-estrutura e equipamentos técnicos, como: berços de atracação, armazéns, frigoríficos, balanças, navios, contêineres, guindastes, empilhadeiras, etc. A função são as atividades desempenhadas pelo porto e por estes equipamentos para realização dos seus objetivos, no caso a movimentação das mercadorias. A estrutura é a articulação entre forma e função, ou seja, a engrenagem, que acionada dá movimento à circulação de produtos. O processo são os acontecimentos contínuos que ocorrem para atender aos objetivos portuários (importação e exportação). Mais uma vez a idéia de totalidade é reforçada por Santos quando diz que, 


\title{
O sistema portuário e a intencionalidade do meio técnico-científico- informacional
}

Considerando o conceito de meio técnico-científico-informacional discutido por Santos, esse

\begin{abstract}
se apresenta como o momento histórico em que a construção ou reconstrução do espaço se dará com a presença de um crescente conteúdo de ciência, de técnicas e de informação nos processos de remodelação do território, essenciais às produções hegemônicas, que necessitam desse novo meio geográfico para sua realização (SANTOS, 2005a).
\end{abstract}

Os portos são objetos dotados de técnica, ciência e informação, elementos inerentes às atuais necessidades da produção. Sendo assim, Santos define esses diferentes elementos dizendo que,

\begin{abstract}
o objeto é científico graças à natureza de sua concepção, é técnico por sua estrutura interna, é científico-técnico porque sua produção e funcionamento não separam técnica e ciência. $\mathrm{E}$ é, também, informacional porque, de um lado, é chamado a produzir um trabalho preciso - que é uma informação - e, de outro lado, funciona a partir de informações. Na era cibernética que é a nossa, um objeto pode transmitir informação a outro objeto (SANTOS, 2008a, p. 215).
\end{abstract}

Nos últimos anos têm se observado uma crescente especialização do transporte de cargas nos portos brasileiros, em virtude da produção. No dizer de Santos,

\begin{abstract}
sem a aceleração contemporânea, a competitividade que permeia o discurso e a ação dos governos e das grandes empresas não seria possível, nem seria viável sem os progressos técnicos recentes e sem a correspondente fluidez do espaço. A exigência de fluidez manda baixar fronteiras, melhorar os transportes e comunicações, eliminar os obstáculos à circulação do dinheiro e suprimir as rugosidades hostis ao galope do capital hegemônico (SANTOS,1994, p. 34).
\end{abstract}

De acordo com Figueiredo (2010), a localização dos portos é dada com o intuito de atender o papel a que estão designados a desempenhar, de modo que seja possível a concretização de sua intencionalidade, ou seja, a realização de sua função predeterminada.

No Brasil estão sendo criados portos dotados de equipamentos e infraestruturas destinadas a atender demandas específicas. Como é o caso do porto de Vila do Conde, no Pará, especializado na exportação de Alumínio. 
Também tem ocorrido a atribuição de "novas funções a velhos portos", como é o caso do porto de Cáceres no Mato Grosso, que antes movimentava diversos produtos e hoje opera predominantemente a soja, do porto privatizado do Rio Grande do Sul, que ganhou um terminal destinado à movimentação de autopeças e automóveis e ainda, o caso do gigante porto de Santos, maior do Brasil e da América Latina, que inicialmente era o principal terminal de exportação de café do país, quando na década de 70 foi equipado por diversos objetos técnico-científicos podendo assim, atender novas demandas.

Portanto, percebe-se que "o sistema de engenharia é reorganizado em função dessas grandes empresas que escolhem localizações de modo a contar com portos quase privativos" (SANTOS; SILVEIRA, 2004). Nesse sentido, podemos mencionar também o porto ilha de Areia Branca-RN, destinado exclusivamente ao transporte do sal produzido no Rio Grande do Norte e dotado de diversos equipamentos específicos para movimentação do produto.

Considerando os portos do Nordeste, mais especificamente o de Pecém no Ceará e o de Suape em Pernambuco, concorrentes do porto de Natal, percebe-se as diferenças entre o porto norteriograndense e os outros dois. Eles apresentam melhor infra-estrutura, como: maior espaço físico, maiores calados, etc. e possuem mais equipamentos especializados. O que coloca o porto de Natal em condição de desvantagem no que diz respeito aos aspectos técnicocientíficos.

De acordo com Ornelas,

Os portos são exemplos de objetos que demandam uma série de outros objetos para o seu funcionamento, tais como: vias de circulação, instalações para armazenagem de cargas, aparatos logísticos, aparelhagem para carga e descarga de mercadorias dos navios, dentre outros (ORNELAS, 2008, p. 78).

Segundo Goebel,

A informática e os modernos meios de telecomunicação também têm se tornado aliados importantes da logística e do transporte intermodal, ao facilitarem o controle e o planejamento das operações. O EDI (Electronic Data Interchange) é uma ferramenta da atualidade que permite a transmissão instantânea dos dados entre o computador dos operadores de transporte e usuários (GOEBEL, 1996). 
Considerando os elementos mencionados acima, veremos a seguir de que modo os objetos necessários para movimentação das mercadorias em estudo no porto de Natal, contribuem para circulação das mesmas.

\title{
Infra-estrutura portuária e equipamentos técnicos: as especificidades dos produtos
}

O porto de Natal utiliza-se de diversos objetos científico-técnicos para execução de suas atividades de movimentação e transporte de cargas. Dentre os produtos analisados na pesquisa, existem algumas especificidades quanto aos objetos utilizados por eles para realização dessa movimentação. Os produtos exportados podem chegar ao porto no dia do embarque ou dias antes. Neste caso, a carga conteinerizada permanece no pátio de contêineres e a não conteinerizada, fica alocada no armazém, até o dia de ser transportada.

Para detalhamento dos equipamentos e infra-estruturas utilizadas, o melão, a manga e o camarão serão reunidos inicialmente num único grupo. Estes produtos, por necessitarem de refrigeração, são acondicionados desde a localidade de origem em contêineres refrigerados, de tamanho variado, podendo ser de $20^{\circ}$ ou de $40^{\prime 3}$. A refrigeração destes contêineres é feita por um gerador a diesel, chamado Genset.

De acordo com Contel,

\begin{abstract}
Um bom índice da modernização do sistema de movimento aquaviário são os fluxos de contêineres. Utilizados pelas cargas que necessitam de um acondicionamento especial, por serem frágeis e de "valor agregado" maior (automóveis, eletroeletrônicos, alimentos sofisticados, etc), esse tipo de transporte é altamente representativo dos fluxos desse período técnico científico informacional (CONTEL, 2004, p. 360-361).
\end{abstract}

Portanto, considerando somente o fluxo de contêineres, pode-se dizer que o porto de Natal demonstra indicativos de modernização desde 2008, em função do aumento significativo desse fluxo.

\footnotetext{
3 Os valores $20^{\prime}$ e $40^{\prime}$ referem-se as dimensões dos contêineres. Os de $20^{\prime}$ apresentam comprimento de $6.058 \mathrm{~mm}$, largura de $2.438 \mathrm{~mm}$ e altura de $2.591 \mathrm{~mm}$, já os contêineres de $40^{\prime}$ possuem comprimento de $12.192 \mathrm{~mm}$, largura de $2.438 \mathrm{~mm}$ e altura de $2.591 \mathrm{~mm}$. Esses valores correspondem as suas dimensões externas.
} 
O quartzo transportado pelo porto de Natal também é armazenado em contêineres de tamanho variável (20` ou 40'), entretanto não-refrigerados. São os chamados contêineres "dry" ou contêineres "carga seca".

Segundo Medeiros,

O processo de conteinirização alterou e continua influenciando fortemente a competitividade na atividade portuária, tanto no que diz respeito às mudanças de infra-estrutura (necessidade de maiores calados, pátios para contêineres, capacidade de carga do cais), instalações e equipamentos especializados para o manuseio (empilhadeiras tipo "top-loader", "stackers", "portainers", "transtainers", guindastes) como também pelas alterações decorrentes do incentivo à intermodalidade (MEDEIROS, 2005, p. 34).

O porto de Natal aumentou recentemente o seu calado, de $10 \mathrm{~m}$ para $12,5 \mathrm{~m}$, o que permite a circulação de navios de maior porte no seu canal de acesso e consequentemente a condução de maior quantidade de contêineres, o que tem contribuído para melhorar sua competitividade em relação aos demais portos da região nordeste.

Segundo Medeiros,

\begin{abstract}
Dentre os vários efeitos da conteinerização sobre a competitividade portuária, estão também as mudanças relacionadas à redução na necessidade de uso de mão-deobra e o incremento dos sistemas informatizados de controle e gerenciamento logístico. A partir da pressão da conteinirização, a disponibilidade de sistemas de informação tecnológica integrada está também assumindo uma posição de destaque entre os fatores de competitividade portuária (MEDEIROS, 2005, p. 35).
\end{abstract}

A movimentação dos contêineres refrigerados e dos contêineres "carga seca" na área do porto é realizada por dois tipos de empilhadeiras: a reach stacker e a top loader. Ambas apresentam a mesma função, entretanto com algumas diferenças. A reach stacker é mais moderna e possui uma movimentação mais ágil, podendo chegar a uma altura maior do que a top loader. Nas figuras 02 e 03 essa diferença pode ser notada. São elas que conduzem os contêineres dos caminhões para o pátio de contêineres e do pátio para a área próxima ao navio. 


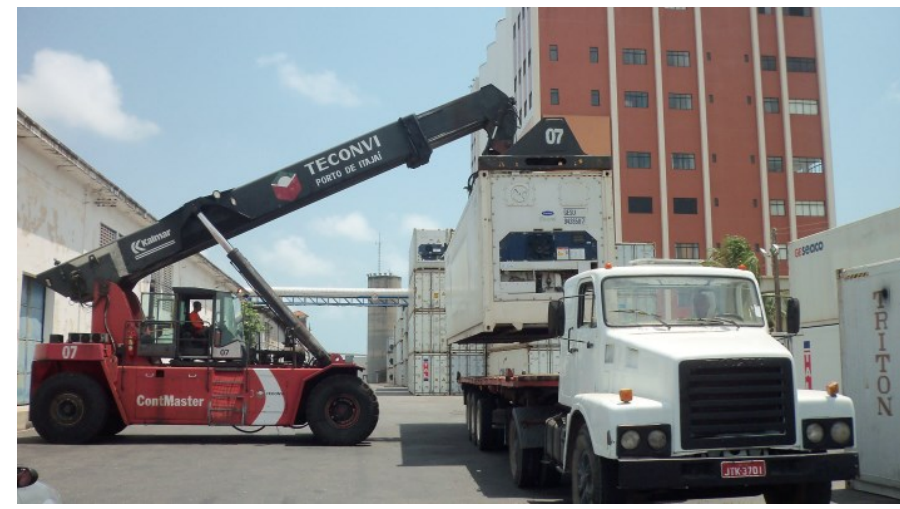

Figura 02: Contêiner sendo retirado do caminhão pela empilhadeira reach stacker Fonte: A autora (2010)

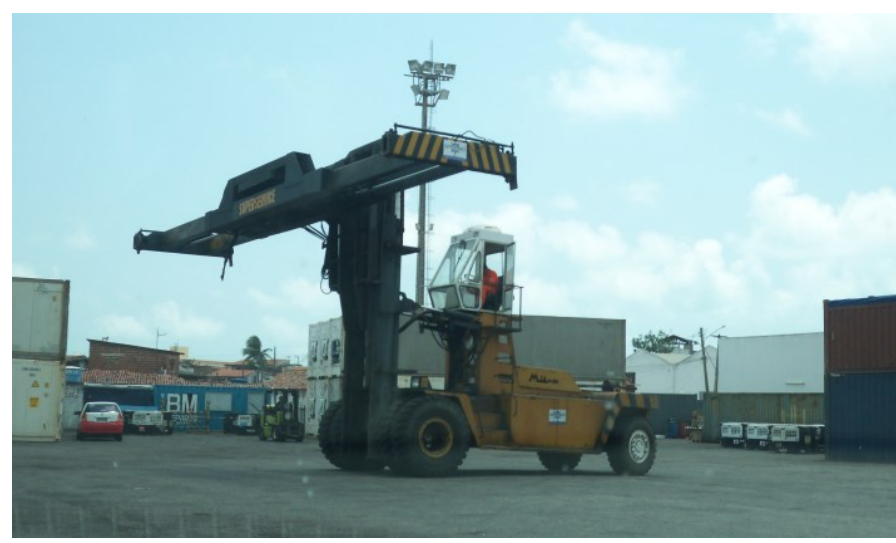

Figura 03: Empilhadeira top loader Fonte: A autora (2010)

Já o açúcar é acondicionado em sacarias e seu agrupamento pode ser realizado por contêineres ou pelo uso de redes. Estas são conduzidas até o embarque diretamente pelo caminhão, sendo transportadas até o navio pelo guindaste de bordo. Essa movimentação feita pelo guindaste, da área próxima ao navio até o seu interior se repete para as demais mercadorias, como pode ser observado na figura 04.

O porto de Natal não possui guindaste de terra, o que limita a movimentação de cargas e causa transtornos nas operações em caso de quebra do guindaste de bordo. 


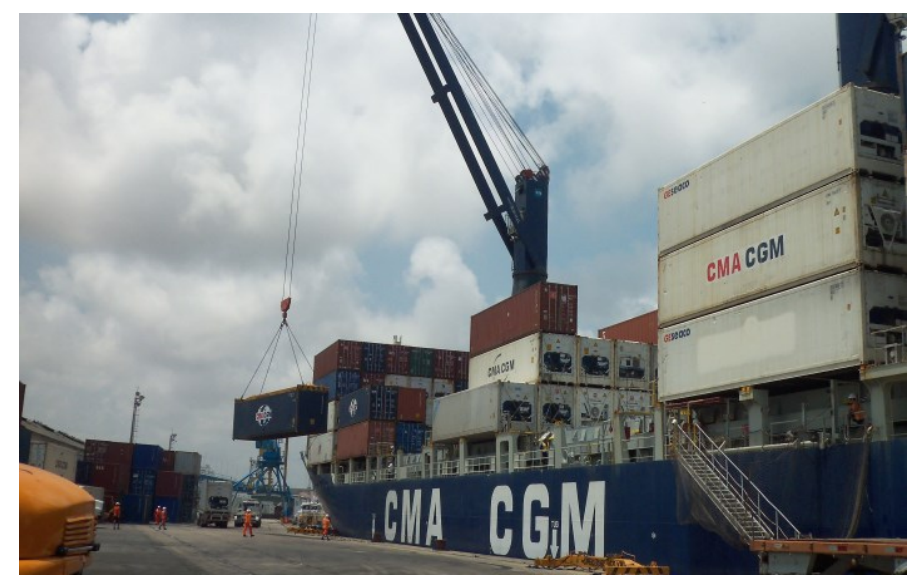

Figura 04: Contêiner sendo transportado para o interior do navio pelo guindaste de bordo.

Fonte: A autora (2010)

O transporte de mercadorias conteinerizadas é feito por navios porta contêineres, as demais, neste caso o açúcar não-conteinerizado, é transportado por navios graneleiros ou navios carga-geral.

De acordo com Santos,

\begin{abstract}
Em nenhuma outra fase da história do mundo, os objetos foram criados, como hoje, para exercer uma precisa função predeterminada, um objetivo claramente estabelecido de antemão, mediante uma intencionalidade científica e tecnicamente produzida, que é o fundamento de sua eficácia. Da mesma forma, cada objeto é também localizado de forma adequada a que produza os resultados que dele se esperam (SANTOS, 2008a, p. 217).
\end{abstract}

Os objetos portuários, ou seja, toda sua infra-estrutura e equipamentos (armazéns, contêineres, empilhadeiras, guindaste, navios, etc) possuem, cada um, uma função específica, aspecto determinante para otimização desses objetos. Eles atuam solidariamente em conjunto, viabilizando a circulação dos produtos e determinando uma dinâmica espacial mais ou menos fluida e intensa. Sua insuficiência e ineficácia podem indicar uma circulação "emperrada" e um porto subutilizado.

\title{
Considerações finais
}

A partir da pesquisa foi possível compreender a forma como o meio técnico-científico-informacional contribui para a movimentação de mercadorias no porto de Natal e como este aspecto é determinante para realização de 
atividades específicas em alguns portos brasileiros. Percebe-se a condição de desvantagem que se encontra o porto de Natal, comparado aos de Pecém-CE e o de Suape-PE, que oferecem melhor infraestrutura e equipamentos técnicos, elementos parcialmente responsáveis por uma melhor fluidez do espaço.

Ainda considerando o meio técnico-científico-informacional, no entanto, do ponto de vista nacional, nota-se a concretização da intencionalidade dos portos, dos quais boa parte atende demandas específicas de produção, funcionando como "portos quase privativos".

Constatou-se que o fato do porto ser responsável pelo transporte de cargas e desse modo fazer parte de um sistema logístico, demanda uma série de objetos atuando solidariamente, de modo a permitir a circulação de mercadorias. Nesse sentido, foram identificados os principais elementos do meio técnico-científico-informacional necessários a essa circulação e os problemas que dificultam sua fluidez. Além disso, foi possível perceber a solidariedade não só entre os equipamentos técnicos, mas também entre as armadoras e as próprias empresas exportadoras, que trabalham em conjunto com intuito de diminuir gastos.

O pequeno número de equipamentos e até mesmo a ausência deles, como é o caso do guindaste de terra, é um destes problemas. Isso ocorre principalmente no período de safra de frutas, quando o porto tem uma concentração das suas operações, o que acaba por dificultar a movimentação dos demais produtos. Nota-se, portanto, o "neodeterminismo" de que fala Milton Santos. Desse modo, as deficiências tecnológicas e estruturais do porto de Natal refletem diretamente na fluidez da circulação e consequentemente na dinâmica espacial.

\section{Bibliografia}

AGÊNCIA NACIONAL DE TRANSPORTES AQUAVIÁRIOS. Porto de Natal. [On-line]: <http://www.antaq.gov.br/Portal/pdf/Portos/Natal.pdf>. [12 de junho de 2010].

ANTAS, Silvano Barbosa Bezerra. Porto de Natal: estrutura, operacionalidade e viabilidade econômica. (Monografia) - Departamento de Geografia, UFRN, Natal, 1997. 
BALLOU, Ronald H.. Logística Empresarial: transportes, administração de materiais e distribuição física. São Paulo: Atlas, 1993.

BERNARDES, Júlia Adão. Circuitos espaciais da produção na fronteira agrícola moderna: BR-163 matogrossense. In: BERNARDES, Júlia Adão; FREIRE FILHO, Osni de Luna. Geografias da Soja: BR 163 Fronteiras em Mutação. Rio de Janeiro: Arquimedes Edições, 2006. Pág. 13-37.

BRASIL. MINISTÉRIO DO DESENVOLVIMENTO, INDÚSTRIA E COMÉRCIO EXTERIOR. Balança Comercial por Unidade de Federação. [On-line]. $<$ http://www.desenvolvimento.gov.br/sitio/interna/interna. php?area=5\&menu=10 78\&refr=1076>. [17 de outubro de 2010].

COMPANHIA DOCAS DO RIO GRANDE DO NORTE - CODERN. Histórico Da Movimentação Geral De Cargas 2004-2010 (em ton): Embarque Geral de Mercadorias Acumulado. Natal: Codern, 2010.

CONTEL, Fabio Betioli. Os sistemas de movimento no território brasileiro. In: SANTOS, Milton; SILVEIRA, María Laura. O Brasil: território e sociedade no início do século XXI. (Estudos de Caso). 6. Ed. Rio de Janeiro: Record, 2004. Pág. 357-374.

FIGUEIREDO, Gustavo Soares. O Papel dos Portos Concentradores na Cadeia Logística Global. Disponível em: <http://www.abepro.org.br/biblioteca/ENEGEP2001_TR11_0464.pdf>. Acesso em: 26 mar. 2010.

FORTUNA, Denizart da Silva. Espaço - Rede, Produtividade e (re)Ordenamento Espacial: notas sobre as (re)interpretações dos "impactos" da rodovia BR-163 na porção norte matogrossense In: BERNARDES, Júlia Adão; FREIRE FILHO, Osni de Luna. Geografias da Soja: BR 163 Fronteiras em Mutação. Rio de Janeiro: Arquimedes Edições, 2006. Pág. 77-98.

GOEBEL, Dieter. Logística: otimização do transporte e estoques na empresa.

[On-line] <http://www.ie.ufrj.br/ecex/pdfs/logistica_otimizacao_do_transporte_e_estoques _na_empresa.pdf>. [26 de março 2010].

MEDEIROS, Aristófanes Dantas de. Fatores Intervenientes na Competitividade dos Portos Brasileiros: Um Estudo de Caso no Nordeste. 154 f. Dissertação (Mestrado) - Departamento de Engenharia de Produção, UFRN, Rio Grande do Norte, 2005.

MOREIRA, Ruy. Pensar e ser em Geografia. São Paulo: Contexto, 2007.

ORNELAS, Ronaldo Dos Santos. Relação Porto/Cidade: o Caso de Santos. [On-line]. <http://www.teses.usp.br/teses/disponiveis/8/8136/tde-10022009123934/pt-br.php>. [10 de março de 2010.

RIBEIRO, Priscilla Cristina Cabral; FERREIRA, Karine Araújo. Logística e Transportes: uma discussão sobre os modais de transporte e o panorama brasileiro.

[On-line]. 
<http://www.abepro.org.br/biblioteca/ENEGEP2002_TR11_0689.pdf>. [26 de março de 2010].

SANTOS, Milton. A Natureza do Espaço: técnica e tempo: razão e emoção. 4. ed. São Paulo: Edusp, 2008a.

A Urbanização Brasileira. 5. ed. São Paulo: Edusp, 2005a.

. Da Totalidade ao Lugar. São Paulo: Edusp, 2005b.

. Espaço e Método. 4. ed. São Paulo: Nobel, 1997.

$2008 b$.

. Metamorfoses do Espaço Habitado. 6. ed. São Paulo: Edusp,

. Técnica, Espaço, Tempo: Globalização e Meio Técnico-Científico Informacional. São Paulo: Hucitec, 1994.

SANTOS, Milton; SILVEIRA, María Laura. O Brasil: território e sociedade no início do século XXI. 6. ed. Rio de Janeiro: Record, 2004.

SECRETARIA DE PORTOS. Sistema Portuário Nacional. [On-line] $<$ http://www.portosdobrasil.gov.br/sistema-portuario-nacional>. [28 de maio 2010].

SILVA, Fabiano Sewiki da; SELLITTO, Miguel Afonso. Sistema hidroviário e portuário do Rio Grande do Sul: visão geral e contextual da infraestrutura.

<http://www.liberato.com.br/upload/arquivos/0105110814223419.pdf>. [30 de maio de 2010.

SILVA, Anelino Francisco da. Natal e Recife: portos em busca de identificação econômica. Natal: UFRN/CCHLA, 1995.

TRIBUNA DO NORTE. Porto de Natal: investimentos que fazem a diferença. [On-line] <http://tribunadonorte.com.br/noticia.php?id=65325>. [28 de março de 2010].

Recebido em 20/08/2012.

Aceito em 20/05/2013. 